\title{
Development of Effective Immunotherapy for the Treatment of Patients with Cancer
}

\author{
Steven A Rosenberg, MD, PhD \\ From the Surgery Branch, National Cancer Institute, National Institutes of Health, Bethesda, MD.
}

\begin{abstract}
In the past two decades, rapid expansion of knowledge in molecular immunology and in understanding the tumor-host immune interaction has opened new possibilities for development of immunotherapies for the treatment of patients with cancer. Immunotherapies have been created that can successfully treat, and probably cure, selected patients with metastatic disease. This review will describe the development of human cancer immunotherapy by considering four sequential questions that have hallmarked progress in recent years (Table 1). Although virtually all of these developments were preceded by laboratory and animal experimentation, this review will deal mainly with the applications of these findings to patients with cancer.
\end{abstract}

\section{Is it possible; can immune stimulation cause regression of established invasive human cancers?}

For most of the 20th century there was no concrete evidence that human cancer antigens existed or that there were any measurable immune responses against growing cancers in patients. A major development in this field was the identification of the antitumor properties of interleukin-2 (IL-2), a secreted cytokine produced by helper T lymphocytes that is a major regulator of immune reactions. The interaction of antigens with $\mathrm{T}$ lymphocytes activates lymphoid cells to express receptors for IL-2, and the simultaneous stimulation of IL-2 secretion leads to the expansion of immune cells and effective immunity.

Shortly after the description of IL- 2 in $1976,{ }^{1}$ the gene encoding IL- 2 was cloned ${ }^{2,3}$ and studies demonstrated that administration of high doses of IL-2 to cancer-bearing mice could result in tumor regression. ${ }^{4} \mathrm{IL}-2$ has no direct impact on cancer cells, so all of the antitumor impact of IL-2 administration is a result of stimulating immune reactions in vivo. Results of the first clinical administration of IL-2 in patients with advanced cancer were published in 1985 and demonstrated that substantial, and sometimes complete, cancer regressions could be mediated in patients with metastatic melanoma and metastatic kidney cancer refractory to other treatments. ${ }^{5-7}$ An update of these studies with a median followup of 11.9 years in 409 consecutive patients with metastatic melanoma or metastatic kidney cancer treated in the

Correspondence address: Steven A Rosenberg, MD, PhD, Surgery Branch, National Cancer Institute, National Institutes of Health, Building 10, Room 2B42, 10 Center Dr, Bethesda, MD 20892..

Presented at the American College of Surgeons 89th Annual Clinical Congress, Chicago, IL, October 2003.

Abbreviations and Acronyms

IL-2

interleukin-2

MHC

major histocompatability complex

TIL 
Surgery Branch, National Cancer Institute with high dose IL-2 alone is shown in Tables 2 and 3 and Figure 1. Complete regressions were seen in $7 \%$ to $9 \%$ of patients and objective partial regressions were seen in $9 \%$ to $10 \%$ of patients (Table 2). The duration of responses of patients achieving a complete response was substantial, and of 33 patients with complete response, 27 remained in complete regression from 46 to 211 months (Table 3). Many of these patients are continuously disease-free beyond 10 years and are probably cured (Fig. 1). These studies, repeated by many groups, led to worldwide approval of IL-2 for the treatment of patients with metastatic melanoma or kidney cancer. An example of two patients achieving a complete response of lung or liver disease are shown in Figures 2 and 3.

Although the number of complete responses was small and only a few solid cancers were susceptible to treatment by IL-2 administration, the principle was established that immune reactions could cause regression of established, invasive human cancer.

These clinical findings set the stage for a variety of studies designed to understand the cellular and molecular basis of these responses with the goal that increased understanding would lead to improvements in the development of more effective cancer immunotherapy.

\section{What are the antigens involved in the immune response against human cancers?}

Recognition of cancer antigens was made possible by identifying, in vitro, lymphocytes that were capable of specifically recognizing cancer cells. Our early studies in experimental animals using tumor infiltrating lymphocytes (TIL) identified such an antitumor population. ${ }^{8,9}$ TILs are lymphoid cells that infiltrate into the stroma of growing cancers and are isolated by growth in IL-2. Early animal studies demonstrated that administration of in vitro expanded TIL cells along with IL-2 could mediate the regression of established lung and liver metastases in a variety of animal models. 8,9

These laboratory studies led to pilot trials in patients with metastatic melanoma who underwent excision of cancer nodules, in vitro growth of the TIL, and then reinfusion of large numbers of expanded TILs, along with their requisite growth factor, IL-2. ${ }^{10,11}$ Results of a pilot trial of TIL cell administration in 73 consecutive patients with metastatic melanoma conducted in the Surgery Branch, National Cancer Institute are shown in Table 4. A 36\% objective response rate was seen in 73 patients, including responses in 7 of 21 patients previously refractory to IL-2 therapy alone. Responding patients often showed a diffuse lymphocyte infiltration into tumors as they underwent clinical regression. By inserting a bacterial gene encoding neomycin phosphotransferase into TILs, it could be shown that at least some of the infiltrating lymphocytes were derived from the infused cells. ${ }^{12}$ These studies represented the first administration to humans of foreign genes and provided a major stimulus to the development of gene therapy approaches to treat patients with cancer and other diseases. ${ }^{13,14}$

The ability to identify lymphocytes capable of recognizing tumor antigens and mediating tumor regression provided a means for cloning the genes that encoded the cancer regression antigens. 15,16 To identify these antigens cDNA libraries containing all genes expressed by the cancer cell were prepared. These genes were then transfected into target cells that expressed the appropriate HLA restriction element but did not express the cancer antigen. The transfected cells were then tested for recognition by TIL that had previously been demonstrated to mediate cancer regression. Proteins encoded by the genes that could convey antigen expression were then characterized.

There are two major classes of T lymphocytes involved in tumor regression. CD8 cells recognize peptides from cancer antigens presented on HLA-A, -B and -C surface molecules (class I major histocompatability complex [MHC] antigens) and $\mathrm{CD} 4$ cells recognize peptides presented on HLA-DR, -DP and -DQ surface molecules (class II MHC antigens). We have 
now identified more than three dozen antigens recognized by CD8 or CD4 T lymphocytes. 15,16 Examples of some of these class I and class II restricted antigens are shown in Tables 5 and 6.

A wide variety of different molecular mechanisms can give rise to cancer antigens. Many melanoma antigens are differentiation antigens also expressed on normal melanocytes, the cells of origin of melanoma. ${ }^{17-19}$ The ability of the tumor to break tolerance to these normal proteins helps explain the significant incidence of vitiligo in patients with melanoma who undergo successful immunotherapy. ${ }^{20}$ Other cancer antigens are encoded by intronic sequences, ${ }^{21}$ by translation of alternative open reading frames, 22 by single base mutations, ${ }^{23}$ or by chromosomal translocations. 24

Although most characterized antigens are present in melanoma, a variety of common epithelial cancers contain target antigens as well (Table 7). A major class of antigens are the cancertestes antigens such as MAGE-1 and NY-ESO-1, expressed only on selected germ cells and in about one-quarter of patients with breast, lung, bladder, esophageal, prostate, and other common cancers. ${ }^{25-28}$ Many cancers, such as hepatomas, Burkitt's lymphoma, Hodgkin's lymphoma, and cervical cancer are associated with viral etiologies, and these viral antigens are often presented on the cell surface. Other cancer antigens are represented by over-expressed oncogenes. So it appears that many common epithelial cancers express antigens that are possible targets of immune attack.

\section{Can antitumor $\mathrm{T}$ cells be generated in vivo by antigen immunization?}

The two major arms of the human immune response involve B cells, largely involved in humoral immune reactions, and T lymphocytes that mediate cellular immunity. The cellular arm of the immune response is predominantly responsible for tissue rejection. In most experimental systems of tissue rejection, transfer of antibodies has little impact; transfer of immune $\mathrm{T}$ cells results in immunologic mediated rejection.

Characterization of the molecular nature of cancer antigens led to a renewal of interest in generating antitumor $\mathrm{T}$ cells in vivo by direct immunization of cancer patients. Most earlier studies involved the use of intact cancer cells or cancer cell lysates and very little evidence of immunization against cancer antigens at the cellular level was seen in these studies. We have conducted trials in more than 1,055 cancer patients exploring optimal methods to immunize and generate $\mathrm{T}$ cells in melanoma patients against the newly identified melanoma-melanocyte differentiation antigens (Table 8). Poor generation of $\mathrm{T}$ cells was achieved when immunizing with recombinant adenovirus, ${ }^{29}$ plasmid DNA,${ }^{30}$ or peptide pulsed dendritic cells. ${ }^{31}$ Immune precursors could be generated when using gp100-expressing fowlpox viruses to which patients do not contain cross reactive antibodies. 32

Immunization of patients using subcutaneous injection of immunogenic peptides emulsified in Incomplete Freund's Adjuvant was the most effective means of generating T cells reactive against cancer antigens. ${ }^{33}$ Most cancer antigen peptides are of relatively low binding affinity to HLA molecules, so it was necessary to modify the anchor amino acid residues in these peptides to increase binding to class I MHC surface molecules. Modification of a threonine to methionine in the second position of the gp100:209-217 peptide from the gp100 melanoma melanocyte-differentiation antigen increased binding to the HLA-A*0201 MHC-Class I antigen about 10-fold, and when this modified peptide was administered to patients, high levels of immune precursors were generated reactive against the native gp 100:209-217 peptide and gp100 expressing melanomas. ${ }^{33,34}$ After two courses of immunization, up to $1 \%$ to $2 \%$ of all circulating CD8 cells had antitumor activity. 
Although T cells could be generated in patients with metastatic cancer, only rare and sporadic antitumor clinical responses have been seen using any form of cancer vaccination to date. A study of cytokine administration along with peptide immunization suggested that IL-2, but not IL-12 or granulocyte-macrophage colony-stimulating factor (GM-CSF), could increase the response rate in patients with metastatic melanoma ${ }^{33}$ (Table 9). A prospective randomized trial is now being performed in melanoma patients treated with either IL-2 alone or peptide immunization plus IL-2.

It appears that despite the ability to generate immune cells reactive against cancer antigens, tumor escape mechanisms can overpower these immune reactions and prevent tumor regression.

\section{Why is tumor regression minimal despite the in vivo generation of antitumor precursors?}

A major aspect of modern research in cancer immunology and immunotherapy is devoted to the study of tumor escape mechanisms that enable the growing cancer to withstand immune attack despite the presence of antitumor T-lymphocytes. 35 A variety of both lymphocyte and tumor-related mechanisms may be involved and are summarized in Table 10.

Most attempts at cancer immunization have involved generation of CD8+ cells, and recent work has demonstrated that CD4+ helper cells are necessary to both activate and sustain the survival of CD8 killer cells. ${ }^{36}$ Immunization against CD4+ class II restricted determinants may be important to improve the efficacy of cancer vaccines. Loss of cancer antigens or loss of expression of HLA antigens have been described in cancer patients, and although these antigens loss variants can occur, they are unusual and do not account for the majority of patients who are refractory to cancer vaccine strategies.

It is possible that the number or avidity of the antitumor cells generated by immunization are insufficient. Administration of quiescent precursors may be ineffective because the tumor does not have the appropriate costimulatory signals that can activate antitumor precursors to a state capable of lysing tumor or secreting cytokines with antitumor properties. Alternatively, regulatory lymphocytes may inhibit the activation of both murine and human lymphocytes. The most promising approach to overcome many of these potential tumor escape mechanisms involves improved methods of cell transfer therapy, and recent studies have demonstrated that this approach is capable of mediating the regression of advanced bulky invasive cancers in $40 \%$ to $50 \%$ of patients with metastatic melanoma refractory to other treatments. 37

\section{Cell transfer therapy after lymphodepletion of the cancer-bearing host}

There are several theoretic advantages to the use of cell transfer therapy for cancer patients. A very large number of cells selected for high avidity for tumor antigens can be administered. By identifying these cells in vitro and assaying for various phenotypic and functional markers, it may be possible to identify the exact cell subpopulations and effector functions required for cancer regression in vivo. In vitro expanded lymphocytes can be activated to exhibit antitumor effector functions, so they do not depend on the activating properties of the tumor. Perhaps most important is the ability to manipulate the host before cell transfer to alter the environment into which the transferred cells are administered. Lymphodepletion before cell transfer can lead to improved homeostatic proliferation of the transferred antitumor cells and can eliminate regulatory cells in the host that may inhibit antitumor reactivities. These host manipulations are not possible with vaccine therapies because they would themselves decrease the number of immune cells capable of reacting to the immunization.

We have recently described a new approach to cell transfer therapy that involves improved methods for growing cells with specific antitumor reactivity 38 and the administration of these 
cells after treatment of the cancer-bearing patient with a nonmyeloablative lymphocyte depleting chemotherapy. ${ }^{37}$ Patients were treated with $60 \mathrm{mg} / \mathrm{kg}$ cyclophosphamide for 2 days and with $25 \mathrm{mg} / \mathrm{m}^{2}$ fludarabine for 5 days before cell administration. This chemotherapy transiently eliminated circulating lymphocytes, and at the height of the lymphodepletion, activated tumor-specific TILs were administered along with IL-2. The chemotherapy regimen is only temporarily ablating and patients began to recover their own neutrophils and lymphocytes approximately 7 to 10 days later.

Using this approach, sustained growth and survival of the transferred cell populations was seen, and in some patients $75 \%$ of all circulating CD8+ cells exhibited antitumor reactivity for up to 2 years after the cell transfer. ${ }^{37}$ Substantial regression of bulky metastatic melanomas was seen at multiple sites including lung, liver, brain, and subcutaneous tissues (Fig. 4 to 9). Six of 13 heavily pretreated patients, refractory to IL-2 treatment alone, achieved an objective cancer regression, and 4 additional patients had substantial mixed or minor responses. An example of the persistence of the administered lymphocytes is shown in Figure 10. ${ }^{37}$ This patient received $1.3 \times 10^{10} \mathrm{~T}$ cells reactive with the MART-1 melanoma melanocyte antigen. These cells grew substantially in the patient and $6.4 \times 10^{10}$ anti-MART-1 lymphocytes were found in the circulation 7 days later. Because only $1 \%$ to $2 \%$ of the body's lymphocytes circulate, this represents almost a 1,000-fold expansion of the transferred cells in the first week after administration. This patient underwent a dramatic cancer regression.

This approach of administering improved antitumor lymphocytes to a lymphodepleted host has for the first time achieved the reproducible persistence of activated lymphocytes with antitumor properties in patients and represents the most successful cancer immunotherapy available to date. All studies performed so far were done in patients with metastatic melanoma, although as indicated in Table 7, immune cells can be generated against antigens present on common epithelial cancers, and efforts to extend these therapeutic observations to patients expressing the NY-ESO-1 cancer-testes antigen are now in progress.

In summary, the field of cancer immunotherapy has evolved slowly, and until recently no reproducible methods for stimulating the human immune system to generate clinically therapeutic immune reactions were possible. But, in the last two decades, progress in the generation of recombinant molecules and a rapid increase in understanding of molecular immunology have enabled the production of recombinant IL-2, which is capable of mediating substantial immune reactivity and cancer regression in patients with metastatic melanoma and metastatic kidney cancer. Molecular biologic techniques have been used to identify the genes encoding cancer antigens, and the immunogenic peptides from these antigens have been identified as well. Immunization strategies have been developed that can generate immune precursors capable of recognizing cancer antigens, and multiple studies are under way to understand the mechanisms involved in the escape of tumor from immune attack. The most effective method to date for using immunotherapy in patients with metastatic cancer involves the adoptive transfer of antitumor lymphocytes into lymphodepleted hosts. Using this approach, substantial cancer regressions can be seen in patients with metastatic melanoma refractory to other treatments. The opportunity to identify the molecular nature of cancer antigens and to generate antitumor immune cells has opened new possibilities for developing effective cancer immunotherapies for the treatment of cancer patients.

\section{REFERENCES}

1. Morgan DA, Ruscetti FW, Gallo RG. Selective in vitro growth of T-lymphocytes from normal bone marrow. Science 1976;193:1007-1008. [PubMed: 181845]

2. Taniguchi T, Matsui H, Fujita T. Structure and expression of a cloned cDNA for human interleukin-2. Nature 1983;302:305-307. [PubMed: 6403867] 
3. Rosenberg SA, Grimm EA, McGrogan M, et al. Biological activity of recombinant human interleukin-2 produced in E. coli. Science 1984;223:1412-1414. [PubMed: 6367046]

4. Rosenberg SA, Mule JJ, Spiess PJ, et al. Regression of established pulmonary metastases and subcutaneous tumor mediated by the systemic administration of high dose recombinant IL-2. J Exp Med 1985;161:1169-1188. [PubMed: 3886826]

5. Rosenberg SA, Lotze MT, Muul LM, et al. Observations on the systemic administration of autologous lymphokine-activated killer cells and recombinant interleukin-2 to patients with metastatic cancer. N Engl J Med 1985;313:1485-1492. [PubMed: 3903508]

6. Lotze MT, Chang AE, Seipp CA, et al. High dose recombinant interleukin-2 in the treatment of patients with disseminated cancer: responses, treatment related morbidity and histologic findings. JAMA 1986;256:3117-3124. [PubMed: 3491225]

7. Rosenberg SA, Yang JC, White DE, Steinberg SM. Durability of complete responses in patients with metastatic cancer treated with high-dose interleukin-2: identification of the antigens mediating response. Ann Surg 1998;228:307-319. [PubMed: 9742914]

8. Rosenberg SA, Spiess P, Lafreniere R. A new approach to the adoptive immunotherapy of cancer with tumor-infiltrating lymphocytes. Science 1986;233:1318-1321. [PubMed: 3489291]

9. Spiess PJ, Yang JC, Rosenberg SA. In vivo antitumor activity of tumor infiltrating lymphocytes expanded in recombinant interleukin-2. J Natl Cancer Inst 1987;79:1067-1075. [PubMed: 3500355]

10. Rosenberg SA, Packard BS, Aebersold PM, et al. Use of tumor infiltrating lymphocytes and interleukin-2 in the immunotherapy of patients with metastatic melanoma. Preliminary report. N Engl J Med 1988;319:1676-1680. [PubMed: 3264384]

11. Rosenberg SA, Yannelli JR, Yang JC, et al. Treatment of patients with metastatic melanoma using autologous tumor-infiltrating lymphocytes and interleukin-2. J Natl Cancer Inst 1994;86:1159-1166. [PubMed: 8028037]

12. Rosenberg SA, Aebersold PM, Cornetta K, et al. Gene transfer into humans: immunotherapy of patients with advanced melanoma, using tumor-infiltrating lymphocytes modified by retroviral gene transduction. N Engl J Med 1990;323:570-578. [PubMed: 2381442]

13. Rosenberg SA, Anderson WF, Blaese M, et al. The development of gene therapy for the treatment of cancer. Ann Surg 1993;218:455-464. [PubMed: 8215637]

14. Rosenberg SA. Gene therapy for cancer. JAMA 1992;268:2416-2419. [PubMed: 1404800]

15. Rosenberg SA. Progress in human tumor immunology and immunotherapy. Nature 2001;411:380384. [PubMed: 11357146]

16. Rosenberg SA. A new era for cancer immunotherapy based on the genes that encode cancer antigens. Immunity 1999;10:281-287. [PubMed: 10204484]

17. Kawakami Y, Eliyahu S, Delgado CH, et al. Identification of a human melanoma antigen recognized by tumor infiltrating lymphocytes associated with in vivo tumor rejection. Proc Natl Acad Sci USA 1994;91:6458-6462. [PubMed: 8022805]

18. Kawakami Y, Eliyahu S, Delgado $\mathrm{CH}$, et al. Cloning of the gene coding for a shared human melanoma antigen recognized by autologous T cells infiltrating into tumor. Proc Natl Acad Sci USA 1994;91:3515-3519. [PubMed: 8170938]

19. Brichard V, Van Pel A, Wolfel T, et al. The tyrosinase gene codes for an antigen recognized by autologous cytolytic T lymphocytes on HLA-A2 melanomas. J Exp Med 1993;178:489-495. [PubMed: 8340755]

20. Rosenberg SA, White DE. Brief report: vitiligo in patients with melanoma: normal tissue antigens can be targets for cancer immunotherapy. J Immunother 1996;183:81-84.

21. Robbins PF, El-Gamil M, Li F, et al. The intronic region of an incompletely spliced gp100 gene transcript encodes an epitope recognized by melanoma-reactive tumor-infiltrating lymphocytes. J Immunol 1997;159:303-308. [PubMed: 9200467]

22. Wang R-F, Parkhurst MR, Kawakami Y, et al. Utilization of an alternative open reading frame of a normal gene in generating a novel human cancer antigen. J Exp Med 1996;183:1131-1140. [PubMed: 8642255]

23. Robbins PF, El-Gamil M, Li YF, et al. A mutated B-catenin gene encodes a melanoma-specific antigen recognized by tumor infiltrating lymphocytes. J Exp Med 1996;183:1185-1192. [PubMed: 8642260] 
24. Wang R-F, Wang X, Rosenberg SA. Identification of a novel major histocompatibility complex class II-restricted tumor antigen resulting from a chromosomal rearrangement recognized by CD4+ T cells. J Exp Med 1999;189:1659-1667. [PubMed: 10330445]

25. Van der Bruggen $P$, Traversari C, Chomez P, et al. A gene encoding an antigen recognized by cytolytic T lymphocytes on a human melanoma. Science 1991;254:1643-1647. [PubMed: 1840703]

26. Boon T, Coulie PG, Van den Eynde B. Tumor antigens recognized by T cells. Immunol Today 1997;18:267-268. [PubMed: 9190110]

27. Jager E, Chen YT, Drijfhout JW. Simultaneous humoral and cellular immune response against cancertestis antigen NY-ESO-1: definition of human histocompatibility leukocyte antigen (HLA)-A2binding peptide epitopes. J Exp Med 1998;187:265-270. [PubMed: 9432985]

28. Wang R-F, Johnston SL, Zeng G, et al. A breast and melanoma-shared tumor antigen: T cell responses to antigenic peptides translated from different open reading frames. J Immunol 1998;161:3596-3606.

29. Rosenberg SA, Zhai Y, Yang JC, et al. Immunizing patients with metastatic melanoma using recombinant adenoviruses encoding MART-1 or gp100 melanoma antigens. J Natl Cancer Inst 1998;90:1894-1900. [PubMed: 9862627]

30. Rosenberg SA, Yang JC, Sherry PM, et al. Inability to immunize patients with metastatic melanoma using plasmid DNA encoding the gp100 melanoma-melanocyte antigen. Human Gene Therapy 2003;14:709-714. [PubMed: 12804135]

31. Panelli MC, Wunderlich J, Jeffries J, et al. Phase I study in patients with metastatic melanoma of immunization with dendritic cells presenting epitopes derived from the melanoma-associated antigens MART-1 and gp100. J Immunother 2000;23:487-498. [PubMed: 10916759]

32. Rosenberg SA, Yang JC, Schwartzentruber DJ, et al. Recombinant fowlpox viruses encoding the anchor-modified gp100 melanoma antigen can generate antitumor immune responses in patients with metastatic melanoma. Clin Cancer Res 2003;9:2973-2980. [PubMed: 12912944]

33. Rosenberg SA, Yang JC, Schwartzentruber DJ, et al. Immunologic and therapeutic evaluation of a synthetic peptide vaccine for the treatment of patients with metastatic melanoma. Nat Med 1998;4:321-327. [PubMed: 9500606]

34. Parkhurst MR, Salgaller ML, Southwood S, et al. Improved induction of melanoma reactive CTL with peptides from the melanoma antigen gp100 modified at HLA-A ${ }^{*} 0210$ binding residues. $\mathrm{J}$ Immunol 1996;157:2539-2548. [PubMed: 8805655]

35. Khong HT, Restifo NP. Natural selection of tumor variants in the generation of "tumor escape" phenotypes. Nat Immunol 2002;11:999-1005. [PubMed: 12407407]

36. Sun JC, Bevan MJ. Defective CD8 T cell memory following acute infection without CD4 T cell help. Science 2003;300:339-342. [PubMed: 12690202]

37. Dudley ME, Wunderlich JR, Robbins PF, et al. Cancer regression and autoimmunity in patients following clonal repopulation with anti-tumor lymphocytes. Science 2002;298:850-854. [PubMed: 12242449]

38. Dudley ME, Wunderlich JR, Shelton TE, et al. Generation of tumor-infiltrating lymphocyte cultures for use in adoptive transfer therapy for melanoma patients. J Immunother 2003;26:332-342. [PubMed: 12843795] 


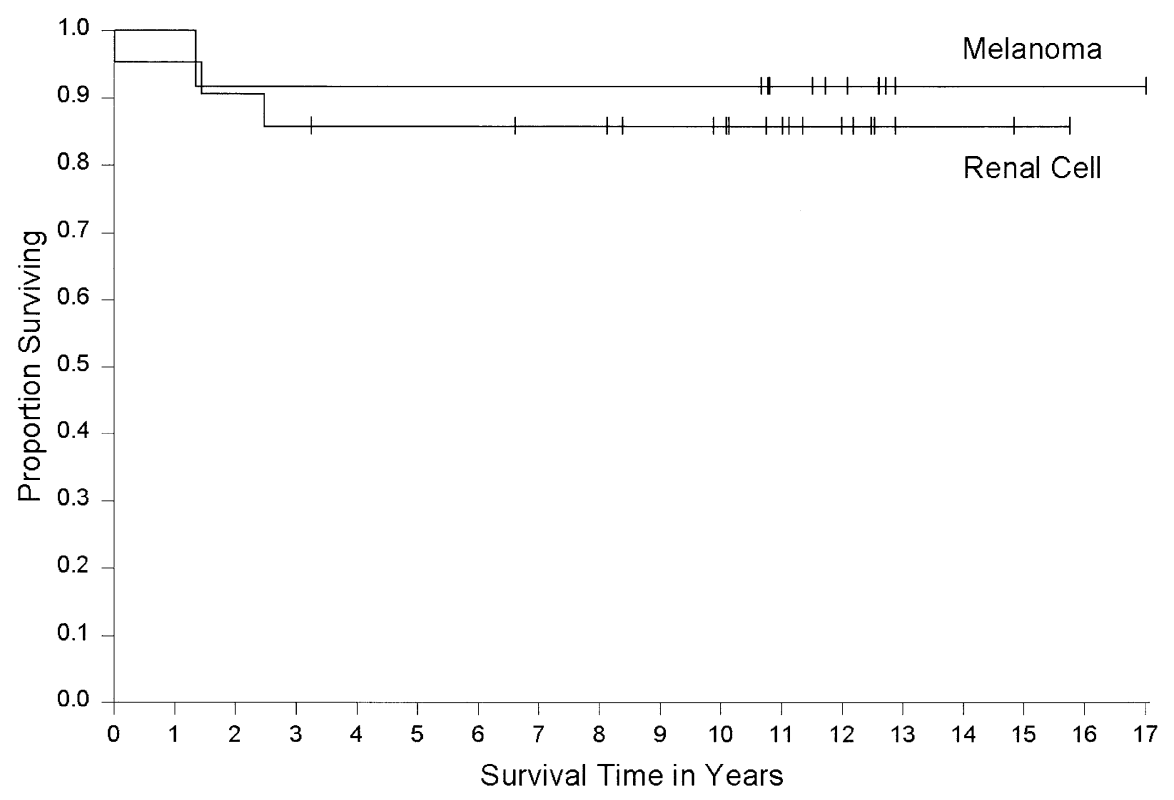

Figure 1.

Actuarial analysis of survival of patients with metastatic melanoma or kidney cancer who experienced complete regression after treatment with high dose interleukin-2 alone (with death from other causes censored). 


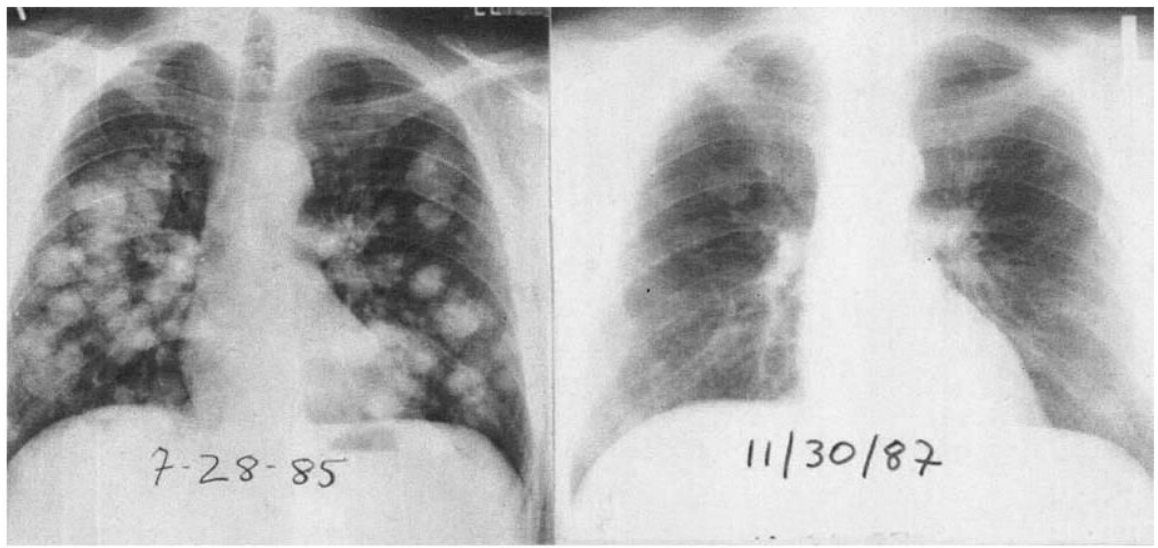

Figure 2.

Complete regression of lung metastases in a patient with melanoma treated with high dose interleukin-2 alone (left, before treatment; right, after treatment). 


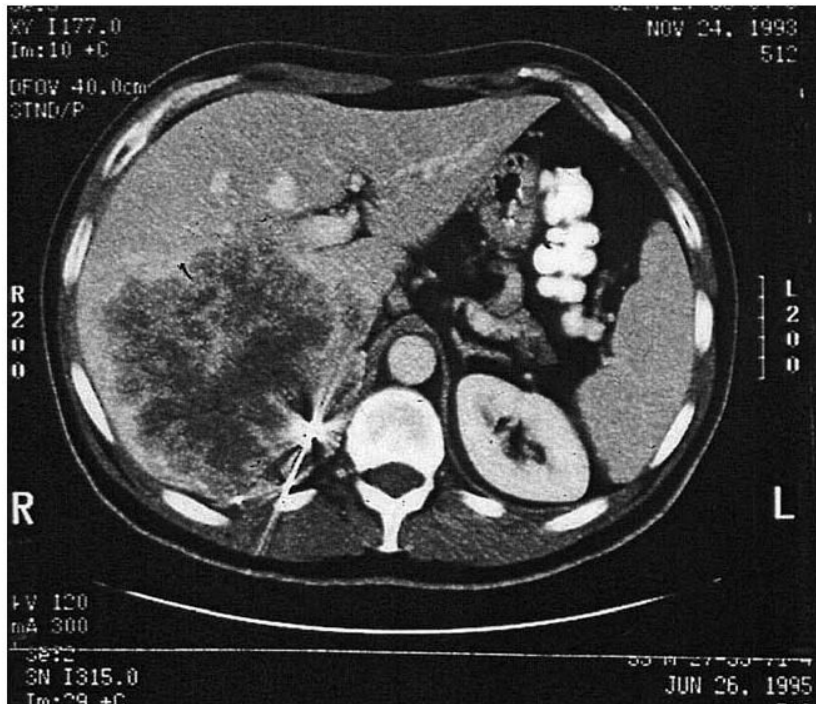

Im: $: 29+C$

JuN 26.1995

[IFOV $40.0 \mathrm{~cm}$

3TM[

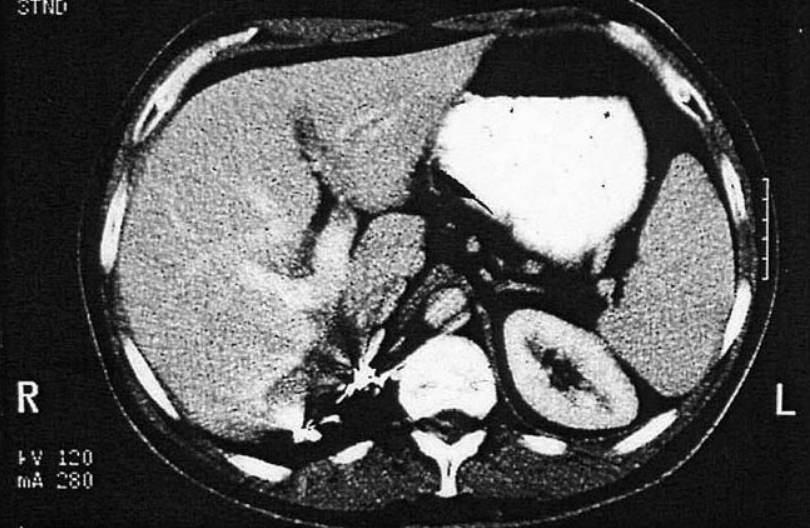

Figure 3.

Complete regression of liver metastasis in a patient with kidney cancer treated with high dose interleukin-2 alone (top, before treatment; bottom, after treatment). 


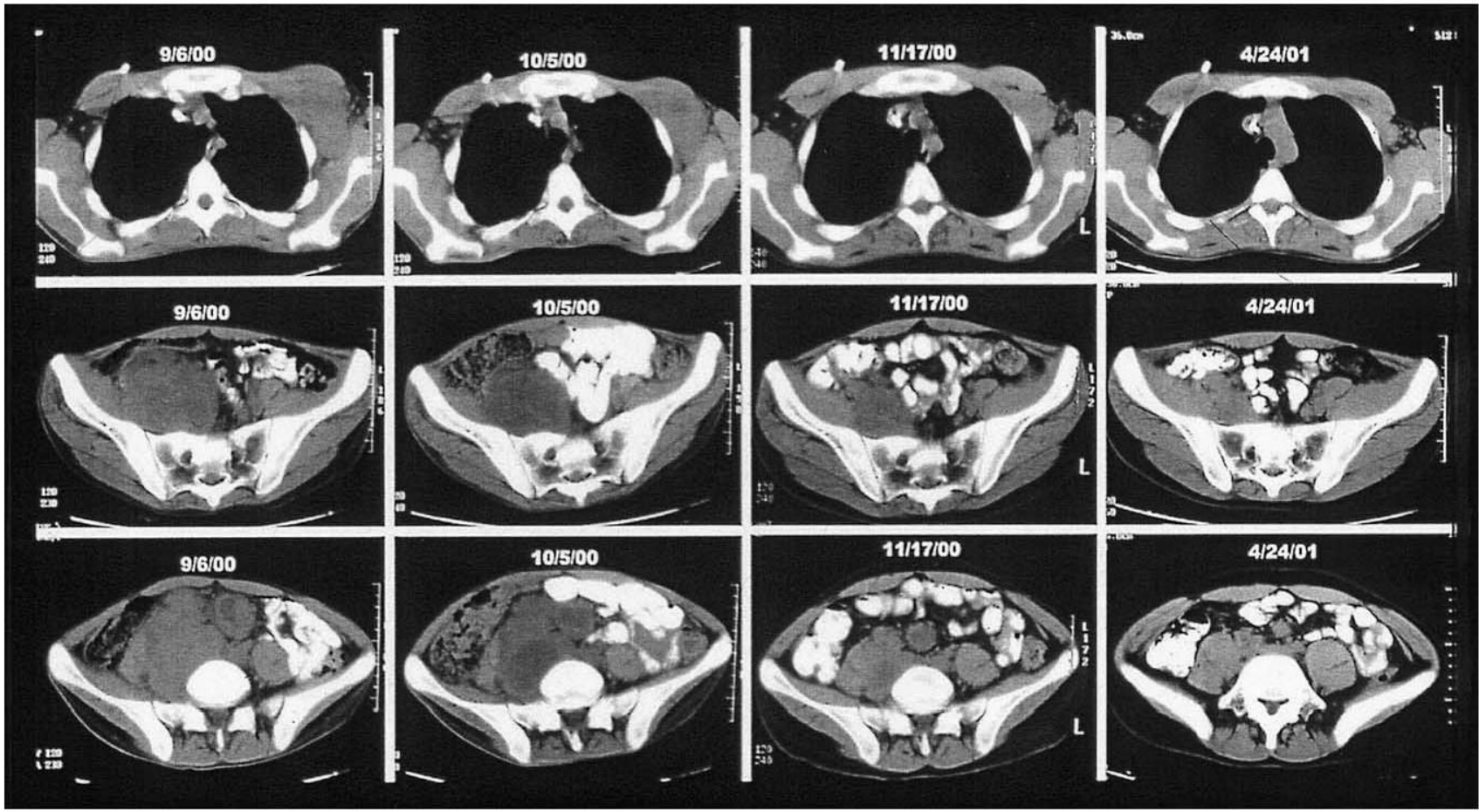

Figure 4.

Regression of bulky axillary (top), pelvic (middle), and intraabdominal (lower) metastases in a patient with melanoma treated with cell transfer after lymphodepletion. 

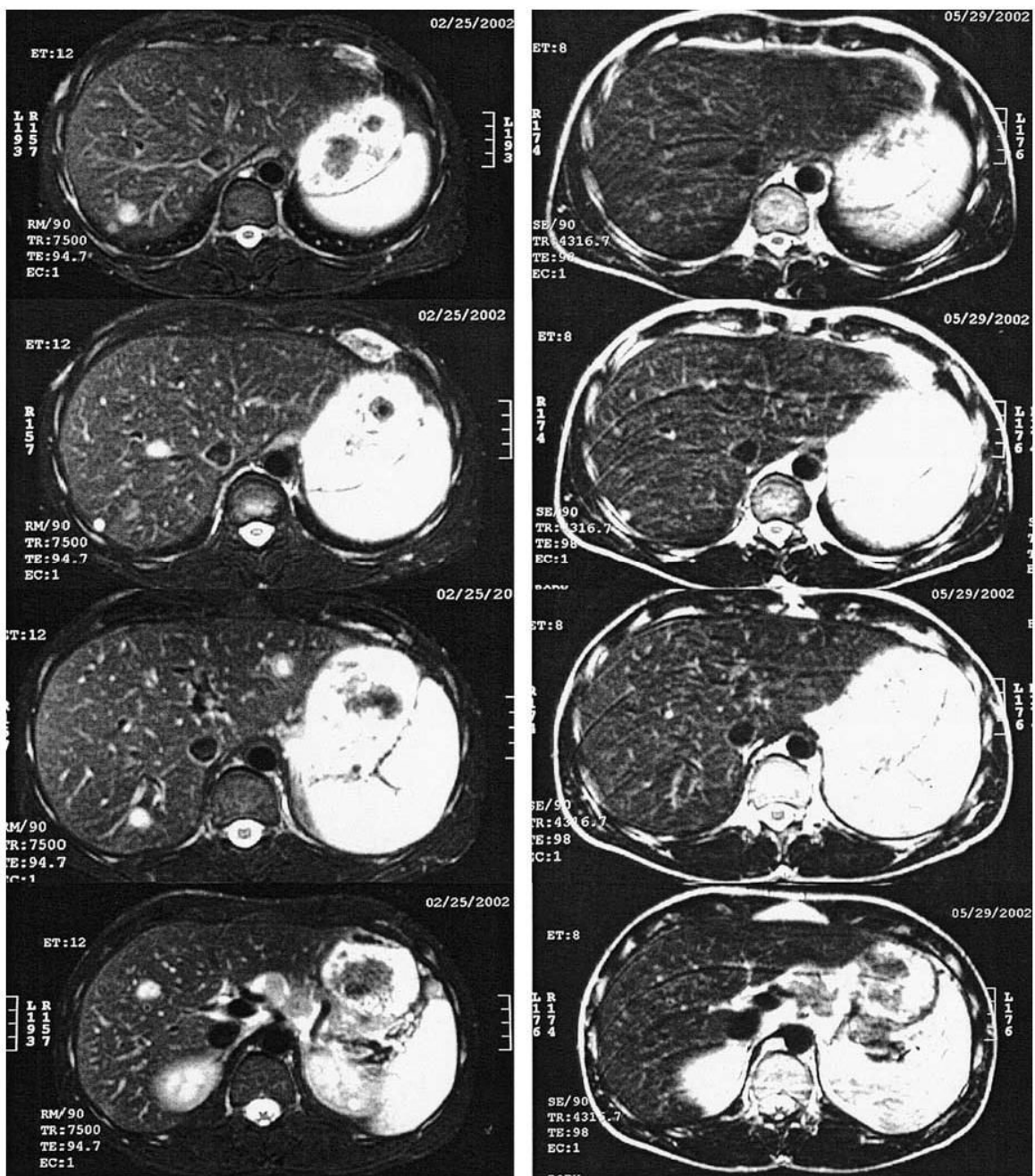

Figure 5.

Regression of liver metastases in a patient with melanoma treated with cell transfer after lymphodepletion (left, before treatment; right, after treatment). 

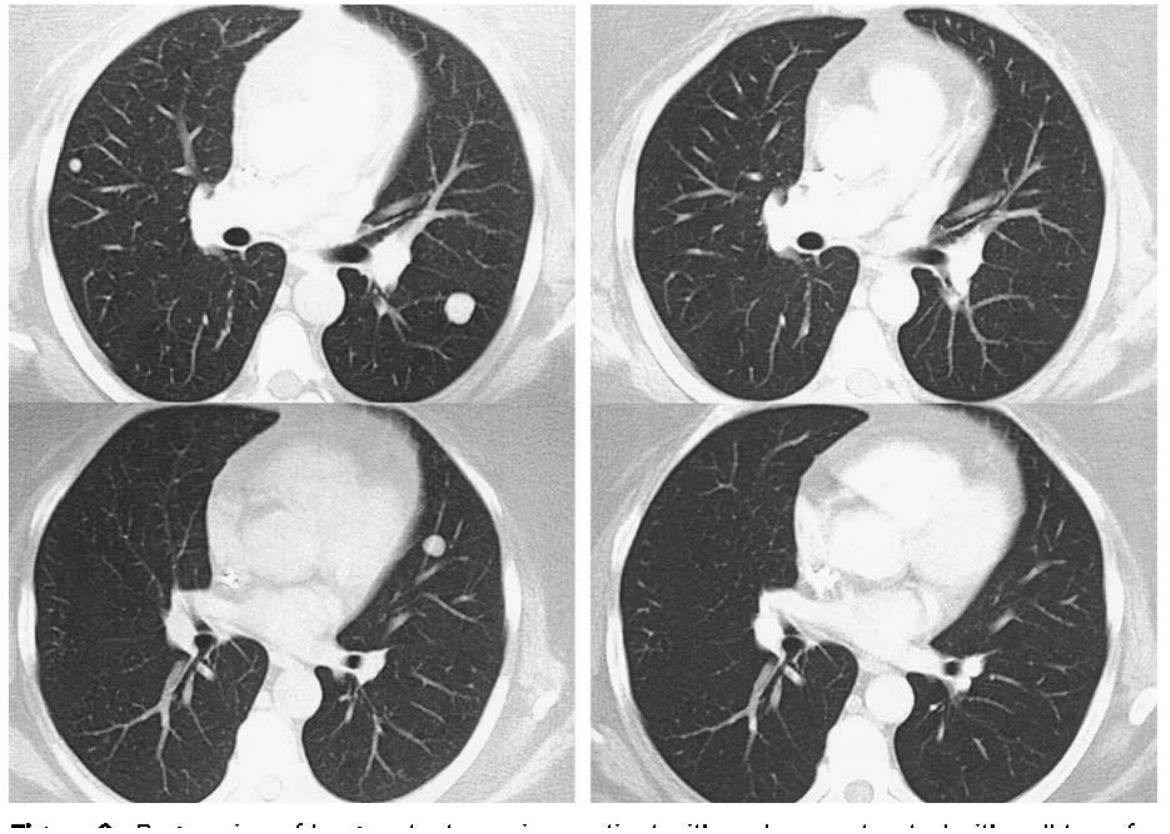

Figure 6.

Regression of lung metastases in a patient with melanoma treated with cell transfer after lymphodepletion (left, before treatment; right, after treatment). 

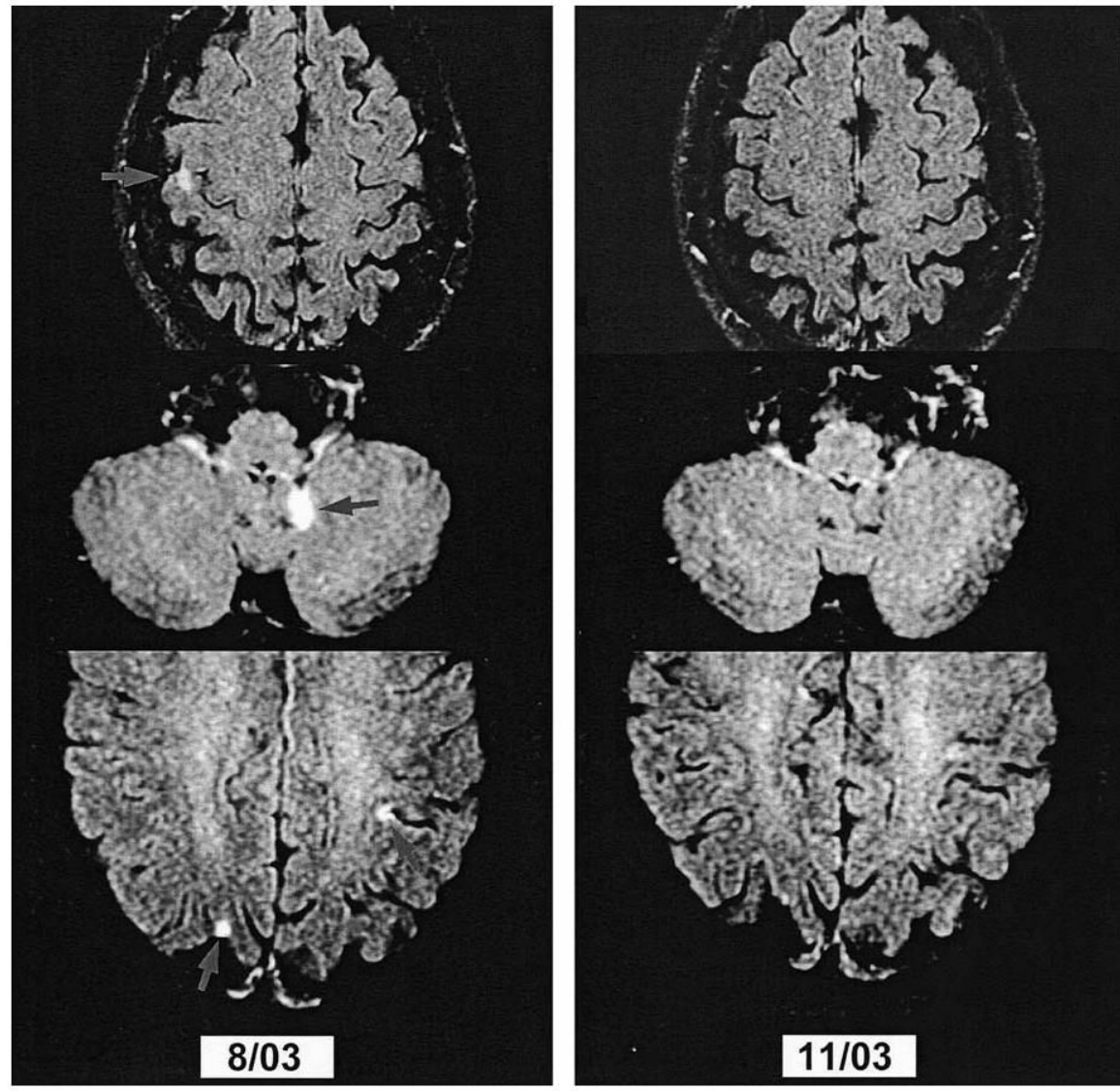

Figure 7.

Regression of brain metastases in a patient with melanoma treated with cell transfer after lymphodepletion (left, before treatment; right, after treatment). 

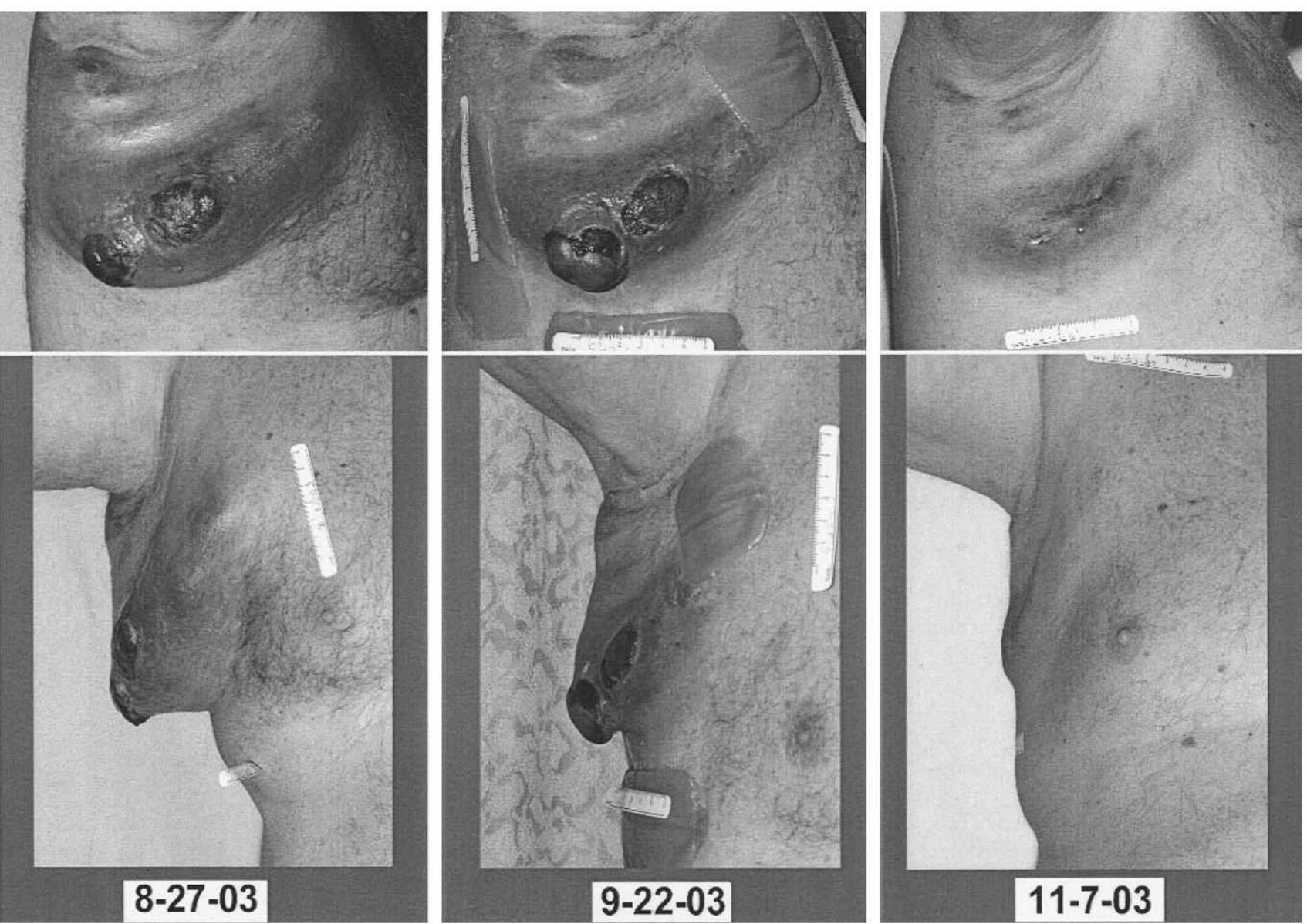

Figure 8.

Regression of bulky axillary metastases in a patient with melanoma treated with cell transfer after lymphodepletion (top, before treatment; bottom, after treatment). 

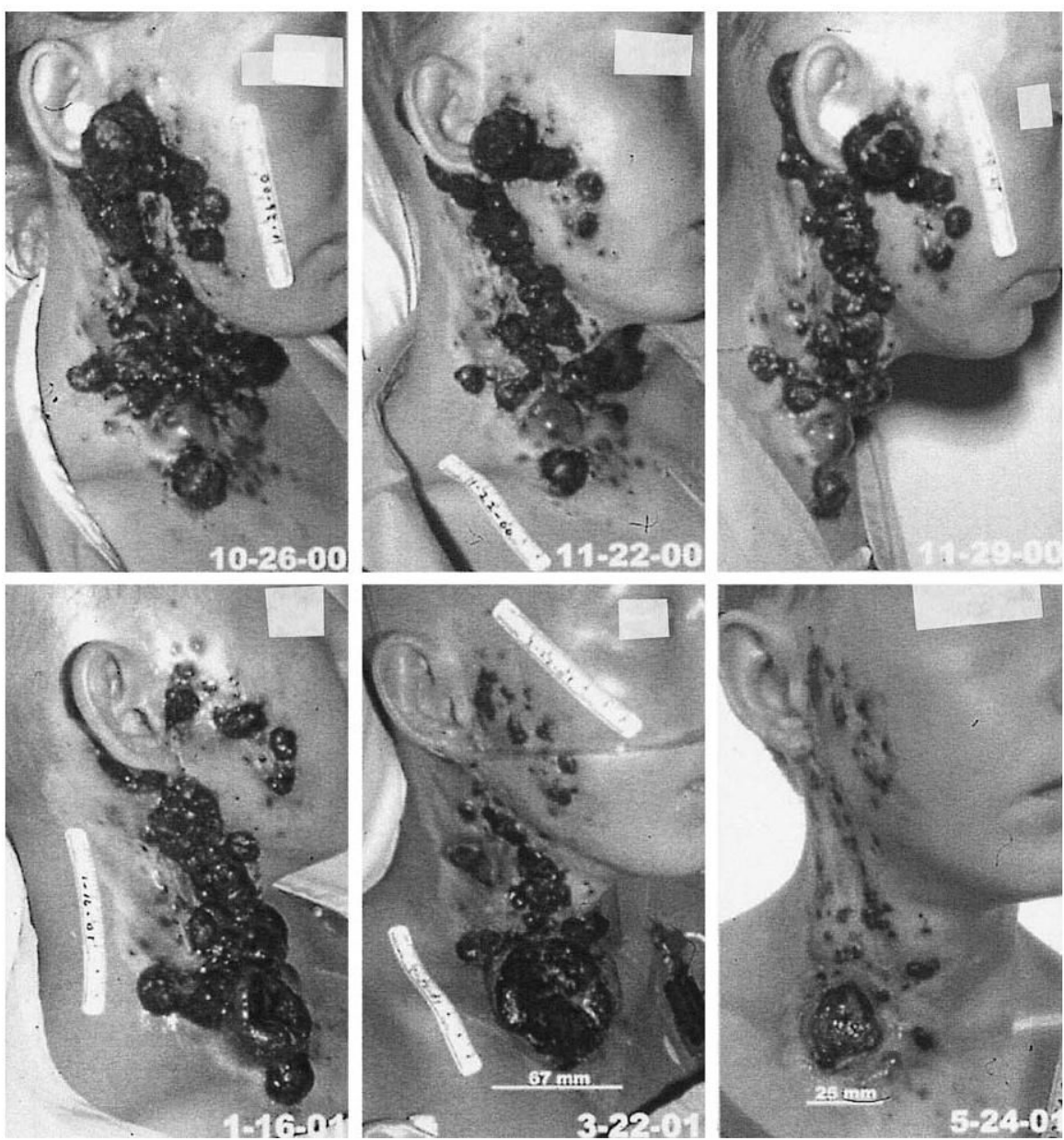

Figure 9.

Regression of cutaneous metastases following sequential treatments in a patient with melanoma treated with cell transfer after lymphodepletion. 


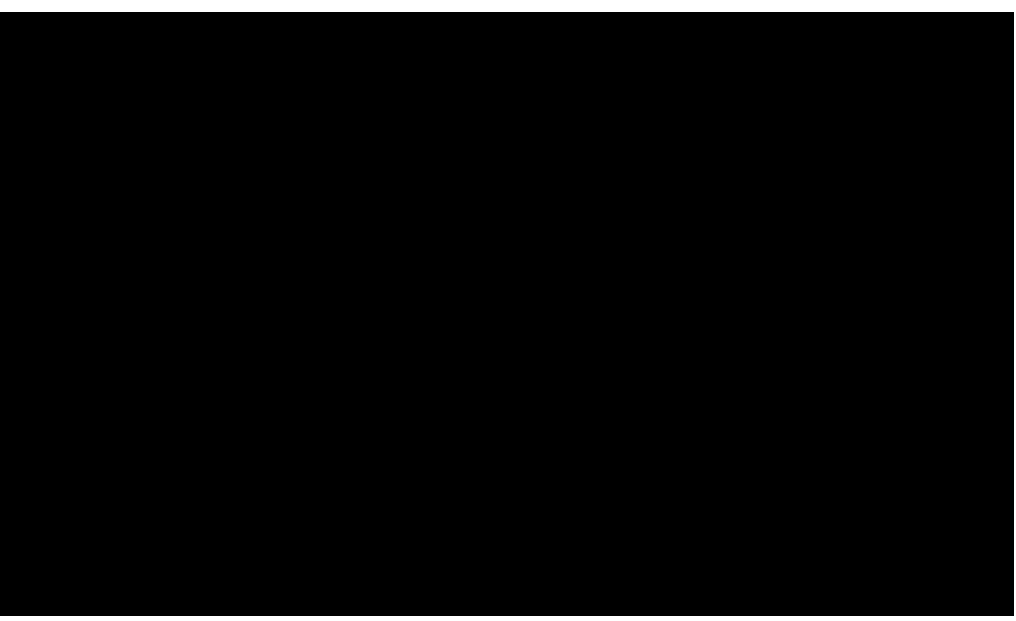

Figure 10.

Persistence of a transferred antitumor T cell expressing the V $\beta$-12 T-cell receptor (TCR) in a patient with melanoma treated with cell transfer after lymphodepletion. The persisting cells also bound to a MART-1 tetramer (A2/M27). 
Table 1

Four Sequential Questions that Have Hallmarked Progress in the Development of Human Cancer Immunotherapy

1. Is it possible? (Can immune stimulation cause the regression of established human cancers?)

2. What are the antigens involved?

3. Can antitumor T-cells be generated in vivo by antigen immunization?

4. What mechanisms limit cancer regression despite the in vivo generation of antitumor T-cells? 
Table 2

Response of Patients with Metastatic Cancer Treated Using High-Dose Bolus Interleukin-2

\begin{tabular}{|c|c|c|c|c|}
\hline Diagnosis & Total n & Complete regression & $\begin{array}{c}\text { n }(\%) \\
\text { Partial regression }\end{array}$ & $\begin{array}{l}\text { Complete regression } \\
\text { + partial regression }\end{array}$ \\
\hline Melanoma & 182 & $12(7)$ & $16(9)$ & $28(15)$ \\
\hline Renal cell cancer & 227 & $21(9)$ & $22(10)$ & 43 (19) \\
\hline Total & 409 & $33(8)$ & $38(9)$ & $71(17)$ \\
\hline
\end{tabular}

Patients accrued between September 1985 and November 1996.

Followup as of June 1, 2003 (median followup 11.9 y). 
Table 3.

Duration of Response in Patients with Metastatic Cancer Treated Using High-Dose Bolus Interleukin-2

\begin{tabular}{lcc}
\hline Diagnosis & Complete regression, mo. & Partial regression, mo. \\
\hline Melanoma & $211+, 160+, 158+, 156+$, & $35,319,19,10,10$, \\
& $154+, 147+, 143+, 134+$, & $8,8,7,7,6,5,5$, \\
& $134+, 133+, 16,12$ & $5,4,4,2$ \\
Renal cell & & $52,30,30,22,20$, \\
cancer & $197+, 186+, 157+, 157+$, & $17,16,15,14,14$, \\
& $153+, 149+, 149+, 142+$, & $13,11,9,8,8,7$, \\
& $140+, 133+, 127+, 126+$, & $7,6,4,4,4,4$ \\
& $123+, 112+, 102+, 87+$, & \\
& $46+, 35,23,19,19$ & \\
\hline
\end{tabular}

“+” indicates ongoing response, as of June 1, 2003.

Of 33 patients with complete response, 27 remain in complete regression at 46 to 211 mo. 
Table 4

Treatment of Patients with Metastatic Melanoma Using Tumor Infiltrating Lymphocytes

\begin{tabular}{cccc}
\hline & Total n & \multicolumn{2}{c}{$\begin{array}{c}\text { Partial regression + complete regression } \\
\mathbf{n}\end{array}$} \\
\hline $\begin{array}{c}\text { No previous interleukin-2 therapy } \\
\text { Previous interleukin-2 therapy } \\
\text { Total }\end{array}$ & 52 & 19 & 37 \\
& 21 & 7 & 33 \\
\hline
\end{tabular}


Table 5

Class I Restricted Melanoma Antigens Recognized by Tumor Infiltrating Lymphocytes

\begin{tabular}{|c|c|c|c|c|}
\hline Name of antigen & $\begin{array}{c}\text { Tumor } \\
\text { infiltrating } \\
\text { lymphocytes } \\
\text { used for } \\
\text { identification }\end{array}$ & HLA restriction & Immunodominant epitopes & Characteristics \\
\hline MART-1 & 1235 and others & A2 & AAGIGILTV & Normal differentiation antigen \\
\hline \multirow[t]{3}{*}{ gp100 } & 1200 and others & A2 & $\begin{array}{l}\text { KTWGQYWQV } \\
\text { ITDQVPFSV } \\
\text { YLEPGPVTA }\end{array}$ & $\begin{array}{l}\text { Normal differentiation antigen } \\
- \\
-\end{array}$ \\
\hline & 1351 & A3 & LIYRRRLMK & - \\
\hline & 888 & A24 & VYFFLPDHL & Intronic sequence \\
\hline \multirow{3}{*}{ Tyrosinase } & $888 \& 1413$ & A24 & AFLPWHRLF & Normal differentiation antigen \\
\hline & 1388 & A1 & SSDYVIPIGTY & - \\
\hline & 1138 & A2 & YMDGTMSQV & - \\
\hline p15 & 1290 & A24 & AYGLDFYIL & Posttranscriptional control \\
\hline b-catenin & 1290 & A24 & SYLDSGIHF & Single base mutation \\
\hline TRP-1 & 586 & A31 & MSLQRQFLR & $\begin{array}{l}\text { Translated from alternative open } \\
\text { reading frame }\end{array}$ \\
\hline TRP-2 & $\begin{array}{l}586 \\
1790\end{array}$ & $\begin{array}{l}\text { A31 } \\
\text { A2 }\end{array}$ & $\begin{array}{l}\text { LLGPGRPYR } \\
\text { SVYDFFVWL }\end{array}$ & $\begin{array}{l}\text { Normal differentiation antigen } \\
-\end{array}$ \\
\hline MART-2 & TIL 1362 & A1 & FLEGNEVGKTY & $\begin{array}{l}\text { Mutation in phosphate binding } \\
\text { loop;loss of ability to bind GTP } \\
\text { Normal differentiation }\end{array}$ \\
\hline AIM-1 & MLT 1300-C22 & A2 & AMFGREFCYA & $\begin{array}{l}\text { antigen;isolated using } \\
\text { immunoselected tumor }\end{array}$ \\
\hline AIM-2MLT & $1300-\mathrm{C} 9$ & A1 & RSDSGQQARY & $\begin{array}{l}\text { Shared on neuroectodermal } \\
\text { tumors (neuroblastoma, Ewing's } \\
\text { sarcoma) }\end{array}$ \\
\hline
\end{tabular}


Table 6

Identification of Class II Restricted Cancer Antigens

\begin{tabular}{|c|c|c|c|c|}
\hline Name of antigen & Method of identification & HLA restriction & Epitope & Characteristics \\
\hline CDC-27 & TIL 1359 & DR4 & FSWAMDLDPKGA & $\begin{array}{l}\text { Mutation resulting in } \\
\text { aberrant processing }\end{array}$ \\
\hline LDLR/FUT & TIL 1363-C22 & DR1 & WRRAPAPGA & \\
\hline TP1 & TIL 155 & DR1 & ELIGILNAAKVPAD & $\begin{array}{l}\text { identification of Topalian } \\
\text { and colleagues }\end{array}$ \\
\hline \multirow[t]{2}{*}{ NY-ESO-1 } & $\begin{array}{l}\text { Peptide screening; } \\
\text { transgenic mice }\end{array}$ & DR4 & VLLKEFTVSG & Cancer-testis antigen \\
\hline & Peptide screening & DR4 & SLLMWITQCFLPVF & $\begin{array}{l}\text { Contains both A2 Class I and } \\
\text { DP Class II epitopes }\end{array}$ \\
\hline TRP-1/TRP-2 & TIL $1541 \mathrm{C} 8$ & DR15 & $\begin{array}{l}? \\
\text { EPSFSLPYWNFATGKNVC } \\
? \\
\text { NESFALPYWNFATGRNEC }\end{array}$ & $\begin{array}{l}\text { Non-mutated; identified by } \\
\text { screening } \\
\text { candidates }\end{array}$ \\
\hline gp100 & $\begin{array}{l}\text { Peptide screening; } \\
\text { transgenic mice } \\
\text { TIL 1290C6 }\end{array}$ & DR15 & WNRQLYPEWTEAQRLD & $\begin{array}{l}\text { Non-mutated; identified by } \\
\text { screening } \\
\text { candidates } \\
-\end{array}$ \\
\hline Ki-67 & TIL $1290 \mathrm{C} 2$ & DR16 & (Pending) & $\begin{array}{l}\text { Mutated; expression limited } \\
\text { to proliferating cells }\end{array}$ \\
\hline
\end{tabular}


Table 7

T-Cell Antigens in Human Cancers

Tumor types

\begin{tabular}{ll}
\hline Antigen & \\
\hline MtAGE & \\
ESO-1 & Treast, lung, bladder, esophagus, prostate,colorectal, head and neck \\
EBNA-1, 2, 3 & Breast, lung, bladder, esophagus, prostate, head and neck \\
HBV surface, core and polymerase & Burkitt's and Hodgkin's lymphoma \\
HPV E6, E7 & Hepatoma \\
Her-2/neu & Cervix \\
rasand p53 & Breast, ovary, pancreas \\
MUC-1 & Many \\
SART-1 & Breast, pancreas, colon, ovary, lung \\
PRAME and RAGE & Squamous head, neck, lung \\
Telomerase & Kidney \\
\end{tabular}


Table 8

Clinical Studies in Patients with Melanoma of Active Immunization with the gp100, MART-1, or Tyrosinase Tumor Antigens (12/95-9/03)

Vector

Recombinant viruses

Adenovirus

Vaccinia

Fowlpox

Vaccinia+ fowlpox (prime boost)

Naked DNA (gp100)

Dendritic cells pulsed with peptide

Peptides

MART-1

gp100 (alone or plus cytokines)

Four peptides (gp100 [ 2], MART-1, Tyrosinase)

Modified gp100 (210M) and MART-1 (27L)

Class II gp100

Non-A2 peptides (includes TRP-2)

Peptides+ FLT-3 Ligand

Peptides + anti-CTLA4

Adjuvant immunization, A2

Adjuvant immunization, Non-A2

Total

These studies were conducted between December 1995 and September 2003.

*

Some patients received more than one immunizing vector in sequential trials. 
Table 9

Clinical Studies of Patients Immunized with gp209-2M Peptide in Incomplete Freund's Adjuvant

\begin{tabular}{lcc}
\hline Cytokine adjuvant & Total objective & Responses \\
\hline None & 11 & 0 \\
IL-2 & 47 & $15(32 \%)$ \\
IL-12 & 21 & 1 \\
GM-CSF & 19 & 0
\end{tabular}

GM-CSF, granulocyte-macrophage colony-stimulating factor; IL, interleu-kin. (From: Rosenberg SA, Yang JC, Schwartzentruber DJ, et al. Immunologic and therapeutic evaluation of a synthetic peptide vaccine for the treatment of patients with metastatic melanoma. Nature Med 1998;4:321-327 with permission.) 
Table 10

Possible Mechanisms of Tumor Escape from Immune Destruction

Lymphocyte factors

Lack of T-cell help

Insufficient number of antitumor T cells

Insufficient avidity of $\mathrm{T}$ cells for tumor

$\mathrm{T}$ cells are "tolerized"

Down-regulation of T-cell receptor signal transduction

Apoptosis of $\mathrm{T}$ cells when encountering tumor

Inadequate T-cell function (cytokines, lysis)

$\mathrm{T}$ cells cannot enter tumor stroma

Inhibition by "suppressor" $\mathrm{T}$ cells

Tumor factors

Tumor cannot activate quiescent precursors

Insufficient tumor antigen expression

Loss of HLA expression by tumor

Tumor produces local immunosuppressive factors

Tumor lacks sufficient apoptotic or other cell destruction

pathways 